\title{
Knockdown of E2F5 induces cell death via the TP53-dependent pathway in breast cancer cells carrying wild-type TP53
}

\author{
YOSHINORI INAGAKI $^{*}$, DAN WU $^{2 *}$, KYOKO FUJIWARA $^{1,3}$, YOSHIAKI ISHIZUKA $^{4}$, \\ ASAKO OGUNI $^{1}$, TOMOHIKO TOKUNAGA ${ }^{1}$, TADATERU TAKAYAMA ${ }^{1}$, MASAYOSHI SOMA ${ }^{1,5}$, \\ NOBORU FUKUDA ${ }^{6}$, TOSHINORI OZAKI ${ }^{7}$ and SHINOBU MASUDA ${ }^{8}$
}

${ }^{1}$ Division of General Medicine, Department of Medicine, Nihon University School of Medicine, Tokyo 173-0032, Japan;

${ }^{2}$ Department of Oncology, The 5th Hospital of Xiamen, Xiamen, Fujian 361101, P.R. China; ${ }^{3}$ Department of Anatomy,

Nihon University School of Dentistry, Tokyo 101-8310; ${ }^{4}$ Department of Pediatric Surgery, Nihon University

School of Medicine, Tokyo 173-0032; ${ }^{5}$ Sasaki Foundation Kyoundo Hospital, Tokyo 101-0062; ${ }^{6}$ Division of Cell Regeneration and Transplantation, Department of Functional Morphology, Nihon University School of Medicine, Tokyo 173-8610, Japan;

${ }^{7}$ Department of DNA Damage Signaling, Research Center, The 5th Hospital of Xiamen, Xiamen,

Fujian 361101, P.R. China; ${ }^{8}$ Division of Oncologic Pathology, Department of Pathology and

Microbiology, Nihon University School of Medicine, Tokyo 173-0032, Japan

Received November 25, 2019; Accepted July 27, 2020

DOI: $10.3892 /$ or.2020.7761

\begin{abstract}
E2F transcription factor 5 (E2F5) is a member of the E2F family of transcription factors, which are involved in regulation of various cellular processes, including cellular proliferation, apoptosis, differentiation and DNA damage response. Previously, we reported that E2F5 was aberrantly overexpressed in estrogen receptor (ER)-negative breast cancer, especially in triple-negative breast cancer (TNBC). In the present study, it was revealed that $E 2 F 5$ gene silencing caused a significant reduction in the proliferation rate of breast cancer MCF7 (ER-positive luminal-type) and MDA-MB-231 (TNBC-type) cells. Additional experiments demonstrated that E2F5 knockdown triggered cell death of MCF7 cells but not MDA-MB-231 cells. As MCF7 and MDA-MB-231 cells carry wild-type and mutant TP53, respectively, and BT474 (ER-negative, HER2-positive type) carrying mutant TP53 exhibited similar results to MDA-MB-231, the possible effects of E2F5 gene depletion on cell death-related TP53-target gene expression were examined. Real-time RT-qPCR analysis
\end{abstract}

Correspondence to: Dr Kyoko Fujiwara, Division of General Medicine, Department of Medicine, Nihon University School of Medicine, 30-1 Oyaguchi-Kamicho, Itabashi, Tokyo 173-0032, Japan E-mail: fujiwara.kyoko@nihon-u.ac.jp

Dr Shinobu Masuda, Division of Oncologic Pathology, Department of Pathology and Microbiology, Nihon University School of Medicine, 30-1 Ohyagushi-kamimachi, Itabashi-ku, Tokyo 173-0032, Japan E-mail: shinobu.masuda@nihon-u.ac.jp

${ }^{*}$ Contributed equally

Key words: breast cancer, E2F5, cell death, gene silencing, TP53 revealed that knockdown of $E 2 F 5$ in MCF7 cells stimulated cell death-related transcription of TP53-target genes such as $B A X$, NOXA and PUMA. For MDA-MB-231 and BT474 cells, E2F5 gene silencing revealed marginal effects on the expression of TP53 target genes. In addition, silencing of TP53 abrogated the effect of E2F5 silencing in MCF7 cells. Collectively, the present results indicated that E2F5 participated in the carcinogenesis of breast cancer carrying wild-type TP53 through suppression of TP53, while E2F5 had a pro-proliferative but not anti-apoptotic effect on breast cancer with TP53 mutation.

\section{Introduction}

Breast cancer is one of the most common malignant tumors and is the leading cause of cancer-related deaths among women worldwide (1). In developed countries, one in between 9 and 12 women develop breast cancer in their lifetime (2). Over the past two decades, the breast cancer mortality rate has decreased due to significant progress in its diagnosis and treatment. As breast cancer is a heterogeneous disease, the response to treatment depends on its biological subtypes.

Breast cancer is generally divided into distinct subtypes i.e., luminal A, luminal B, HER2-enriched, basal-like and normal-like subtypes (3-5). Luminal A- and B-type breast cancers express estrogen receptor (ER), and their growth is regulated in an estrogen-dependent manner. In addition, HER2 is a receptor for epidermal growth factor (EGF) and promotes cell survival through several oncogenic signaling pathways including RAS, AKT and/or mTOR (6,7). Anticancer drugs targeting HER 2 are used in the primary treatment of patients with HER2-enriched-type breast cancer. Breast cancer without ER, progesterone receptor (PgR), and HER2 expression is designated as triple negative breast cancer (TNBC). An extensive search for mutations demonstrated that loss of function mutations are common within TP53, $p R b$ and $B R C A 1$ 
loci in TNBC, suggesting that these mutations are involved in the development of the aggressive phenotypes of TNBC (8).

E2F transcription factor 5 (E2F5) is a transcription factor belonging to the E2F family, which is composed of eight members designated as E2F1-7 and 8 (9). E2F1-3 bind to the hypophosphorylated forms of $\mathrm{pRb}$, and inhibit their cell cycle-regulatory role. E2F4 and E2F5 interact with pRb-related p107/p130 and p130, respectively (10-12). Among E2F family members, E2F5 has been revealed to act as an oncogene for prostate (13), esophageal (14), ovarian (15), and colorectal cancer (16) as well as hepatocellular carcinoma (HCC) (17). Several lines of evidence suggest that E2F5 has a tumor-suppressive role in HCC (18) and non-small cell lung cancer (19). A study using the Oncomine and Cancer Genome Atlas databases revealed that E2F5 was upregulated in breast cancer compared to normal tissue and overexpression of E2F5 mRNA was related to lower rate of relapse-free survival and post-progression survival (20). We reported previously that E2F5 was overexpressed in ER-negative breast cancer, especially in TNBC (20). Based on our results, the E2F5-positive subgroup exhibited a higher histological grade, greater rate of ER and PgR negativity, and a higher Ki-67 labeling index than those in the E2F5-negative subgroup. Moreover, among the patients without the lymph node metastasis, the E2F5-positive subgroup exhibited a significantly shorter disease-free survival period than the E2F5-negative subgroup. Therefore, it was speculated that E2F5 may act as an oncogene for breast cancer.

However, it remains unclear how E2F5 could contribute to the development and/or progression of breast cancer. The genomic amplification and/or hypomethylation of $\mathrm{CpG}$ islands within the $E 2 F 5$ promoter region were revealed to result in the aberrant overexpression of E2F5 $(21,22)$. Mutant TP53 contributed to inhibition of E2F5 via microRNA-182-2, and resulted in suppression of $\mathrm{p} 21^{\mathrm{WAF} 1}$ and cell survival (19).

In the present study, it was revealed that E2F5 participated at least in part in the carcinogenesis of breast cancer carrying wild-type TP53 through the suppression of TP53, while E2F5 alone was not sufficient for the development and/or maintenance of the malignant phenotypes of TP53-mutant breast cancer.

\section{Materials and methods}

Cell lines and culture conditions. Human breast cancer MCF7, MDA-MB-175VII, BT474 and MDA-MB-231 cells were obtained from American Type Culture Collection (ATCC). MCF7 and BT474 cells were cultured in RPMI-1640 medium (Nacalai Tesque, Inc.) supplemented with $10 \%$ heat-inactivated fetal bovine serum (FBS; Nichirei Biosciences, Inc.). MDA-MB-175VII and MDA-MB-231 cells were maintained in Leibovitz's L-15 medium (Thermo Fisher Scientific, Inc.) containing $10 \%$ heat-inactivated FBS. All of the media contained $100 \mathrm{IU} / \mathrm{ml}$ of penicillin and $100 \mu \mathrm{g} / \mathrm{ml}$ of streptomycin (both from Thermo Fisher Scientific, Inc.). Cells were maintained at $37^{\circ} \mathrm{C}$ in an incubator with a controlled humidified atmosphere consisting of $95 \%$ air and $5 \% \mathrm{Co}_{2}$.

Small interfering (si)RNA-mediated knockdown of E2F5 and TP53. Cells were seeded at a density of $5 \times 10^{4}$ cells $/ \mathrm{ml}$ and allowed to attach on the bottom of culture plate. Twenty-four

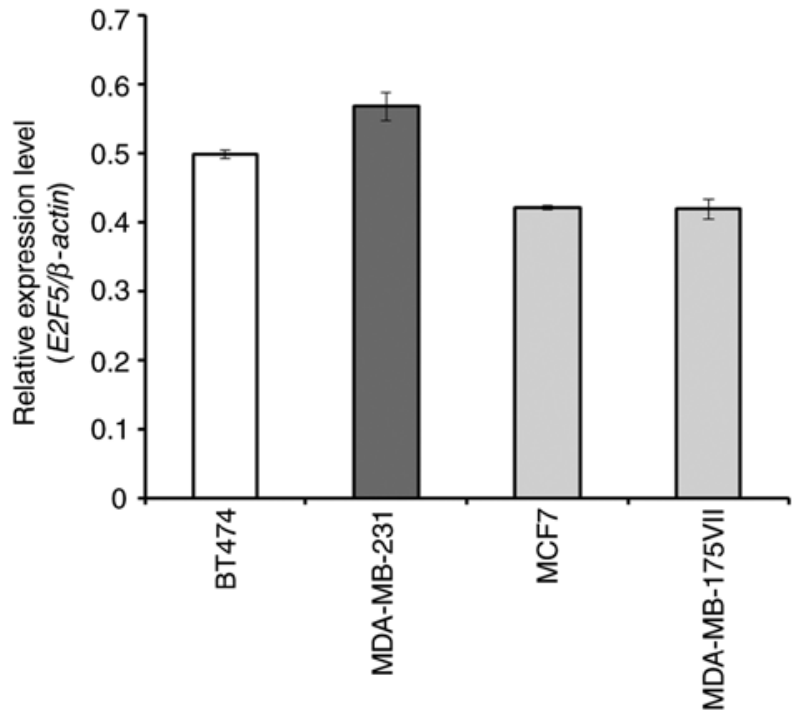

Figure 1. No marked differences are observed in the levels of E2F5 expression among three types of breast cancer cells. Total RNA was prepared from the indicated breast cancer cell lines: MDA-MD-231 (triple-negative, $\mathrm{ER}^{-} /$ HER2 $^{-}$), BT474 (HER2, ER ${ }^{-} / \mathrm{HER}^{+}$) and MCF7 plus MDA-MD-175VII (luminal, $\mathrm{ER}^{+}$). Total RNA was analyzed for E2F5 by real-time RT-qPCR. $\beta$-actin was used as an internal control. Data are presented as the means $\pm \mathrm{SD}$ of measurements performed in triplicate. E2F5, E2F transcription factor 5; RT-qPCR, reverse transcription-quantitative PCR.

hours after seeding, cells were transfected with siRNA using Lipofectamine 3000 (Thermo Fisher Scientific, Inc.) in accordance with the manufacturer's instructions. siRNA for E2F5 (siRNA ID s4417; cat. no. 4392420; Thermo Fisher Scientific, Inc.), siRNA for TP53 (cat. no. sc-29435; Santa Cruz Biotechnology, Inc.), and control siRNA (cat. no. 4390843; Thermo Fisher Scientific, Inc.) were used in the present study.

Cell viability and cell cycle distribution. MCF7 and MDA-MB-231 cells were seeded in 96-well culture plates at a density of $5 \times 10^{4}$ cells $/ \mathrm{ml}$ and transfected with E2F5 siRNA or control siRNA $24 \mathrm{~h}$ after seeding. At the indicated time-points, viability of the transfected cells was measured by the standard WST-8 assay using Cell Count Reagent CF (Nacalai Tesque, Inc.). One tenth volume of WST8 solution was added to culture medium and incubated for $1 \mathrm{~h}$ at $37^{\circ} \mathrm{C}$ in $\mathrm{Co}_{2}$ incubator. Then absorbance of culture medium at OD $450 \mathrm{~nm}$ was measured.

For fluorescent-activated cell sorting (FACS) analysis, MCF7 and MDA-MB-231 cells were seeded in 6-well culture plates at a density of $1 \times 10^{5}$ cells $/ \mathrm{ml}$ and transfected with $E 2 F 5$ siRNA or control siRNA $24 \mathrm{~h}$ after seeding. Cells were cultured for 4 days, and then both floating and attached cells were collected for FACS analysis. Cells were washed in PBS and fixed in $70 \%$ ethanol overnight at $4^{\circ} \mathrm{C}$. After washing in PBS, cells were suspended in PBS containing $0.1 \%$ FBS, $25 \mu \mathrm{g} / \mathrm{ml}$ propidium iodide (Sigma-Aldrich; Merck KGaA) and $200 \mu \mathrm{g} /$ $\mathrm{ml}$ of RNase A (Sigma-Aldrich; Merck KGaA), and incubated for $15 \mathrm{~min}$ at room temperature. Subsequently, the cells were subjected to FACS analysis (FACSCalibur; BD Biosciences).

Real-time reverse transcription-quantitative $(R T-q) P C R$. Total RNA was extracted from cells using RNeasy mini kits (Qiagen, Inc.) according to the manufacturer's instructions. 
A

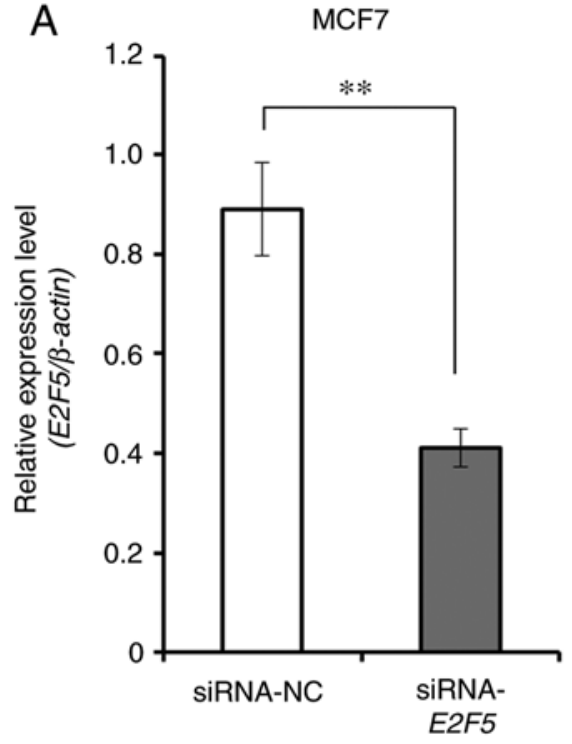

C

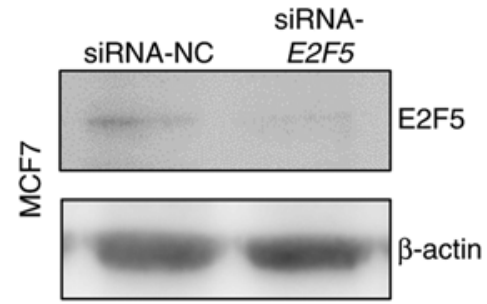

E

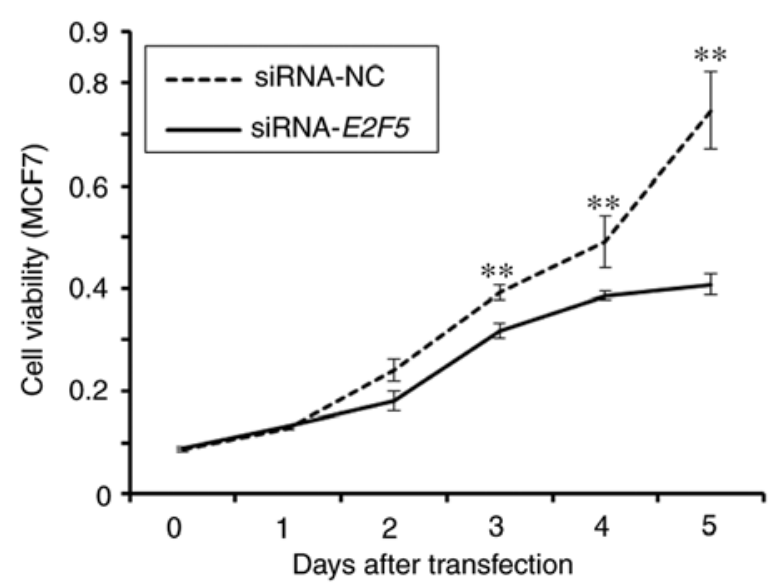

B

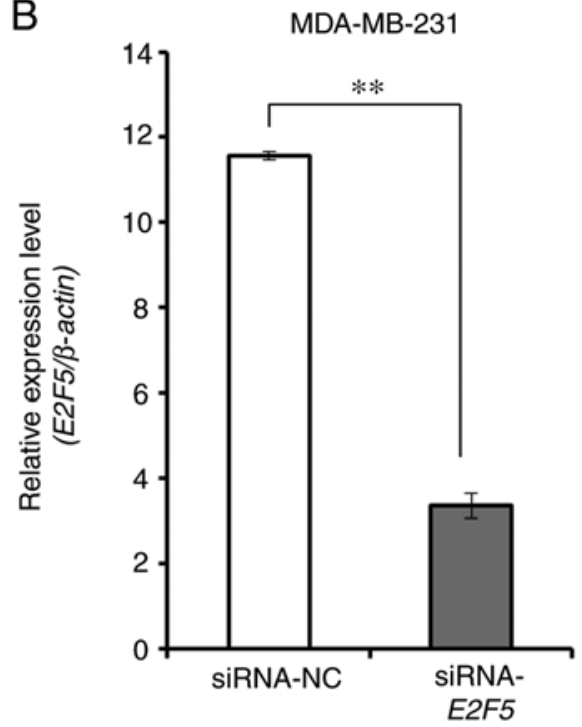

D

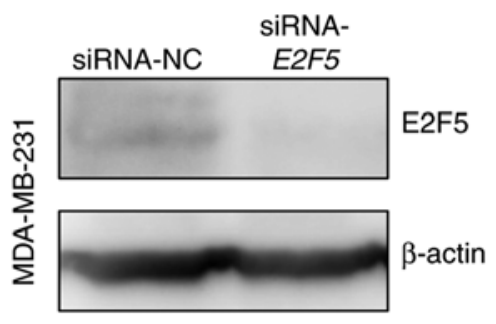

F

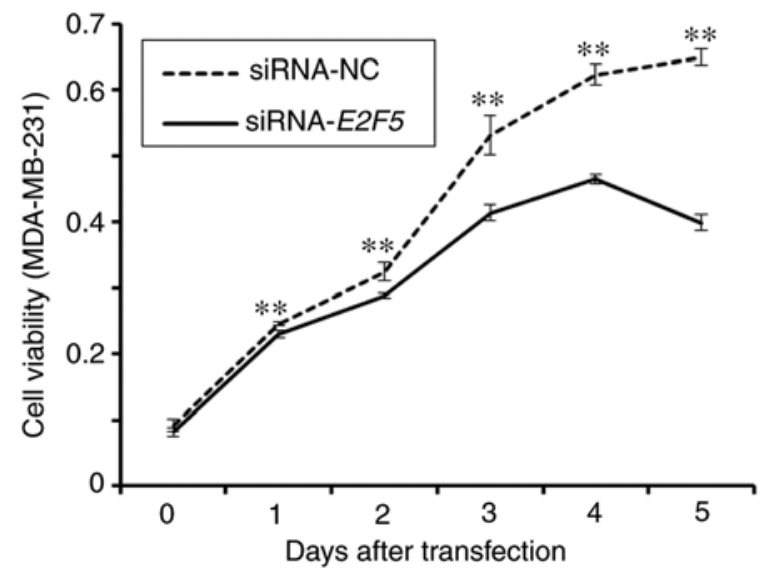

Figure 2. Knockdown of E2F5 expression markedly suppresses the proliferation rates of MCF7 and MDA-MB-231 cells. (A and B) MCF7 and MDA-MB-231 cells were transfected with E2F5 siRNA or control siRNA. Total RNA was extracted $48 \mathrm{~h}$ after transfection, and analyzed for $E 2 F 5$ expression by real-time RT-qPCR. $\beta$-actin was used as an internal control. (C and D) MCF7 and MDA-MB-231 cells were transfected as described in A and B. Whole-cell lysates were prepared $48 \mathrm{~h}$ after transfection and subjected to immunoblotting analysis. $\beta$-Actin was used as a loading control. (E and F) MCF7 and MDA-MB-231 cells were transfected as described in A and B. The viabilities of (E) MCF7 and (F) MDA-MB-231 cells were measured by the standard WST8 assay from 1 to 5 days after transfection with E2F5 siRNA (solid line) or control siRNA (dashed line). Data are presented as the means \pm SD of measurements performed in triplicate. ${ }^{* *} \mathrm{P}<0.01$. E2F5, E2F transcription factor 5; RT-qPCR, reverse transcription-quantitative PCR.

For cDNA synthesis, aliquots of 500 ng of total RNA were reverse-transcribed using iScript cDNA synthesis system (Bio-Rad Laboratories, Inc.). Real-time RT-qPCR for E2F5 and $\beta$-actin was performed using Premix Ex Taq Perfect Real Time (Takara Bio, Inc.) with TaqMan Pre-Developed Assay Reagents (Thermo Fisher Scientific, Inc.), Hs00231092_m1 for E2F5 and Hs99999903_m1 for $\beta$-actin. The reaction was carried out at $95^{\circ} \mathrm{C}$ for $5 \mathrm{sec}$ and $60^{\circ} \mathrm{C}$ for $20 \mathrm{sec}$, for total of 40 cycles. Real-time RT-qPCR for $p 21^{W A F 1}, B A X, N O X A$ and
PUMA was performed using SYBR Premix Ex Taq ${ }^{\mathrm{TM}}$ (Takara Bio, Inc.) according to the manufacturer's recommendations. The primers used were as follows: $p 21^{\text {WAFI }}$, 5'-GCAGAC CAGCATGACAGATTT-3' (sense) and 5'-GGATTAGGG CTTCCTCTTGGA-3' (antisense); BAX, 5'-TTGCTTCAG GGTTTCATCCA-3' (sense) and 5'-AGACACTCGCTCAGC TTCTTG-3' (antisense); NOXA, 5'-GCAGAGCTGGAAGTC GAGTG-3' (sense) and 5'-GAGCAGAAGAGTTTGGATATC AG-3' (antisense); PUMA, 5'-GACGACCTCAACGCACAG 

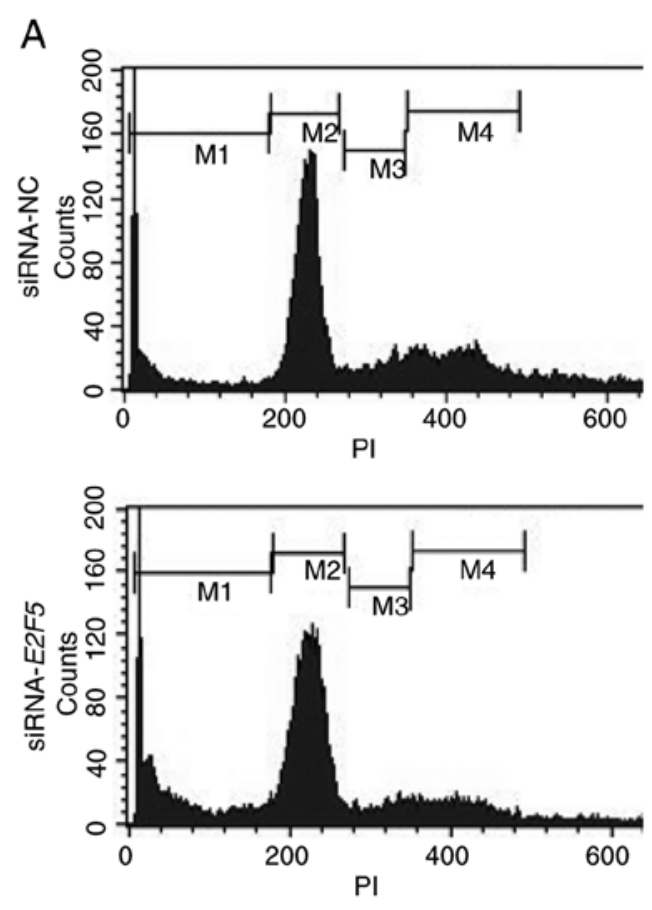

C

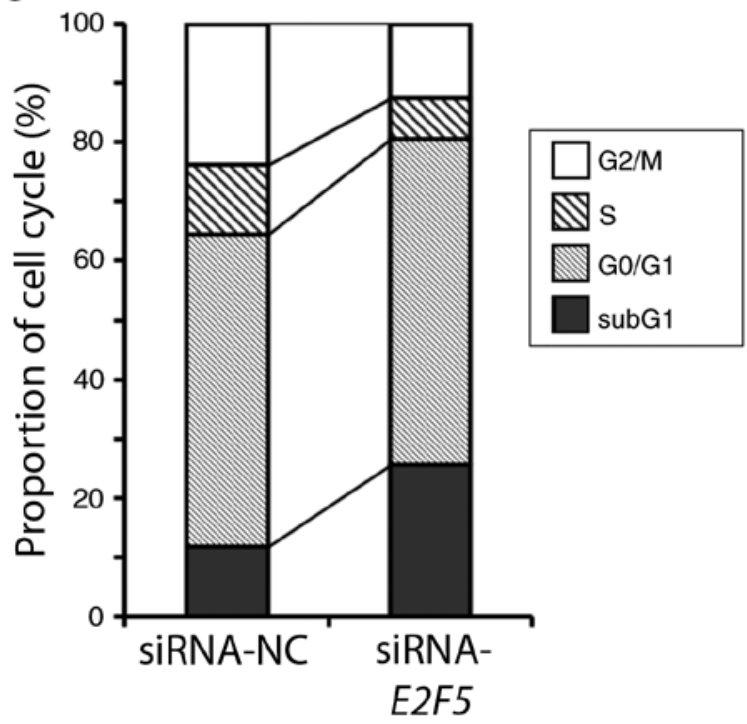

B
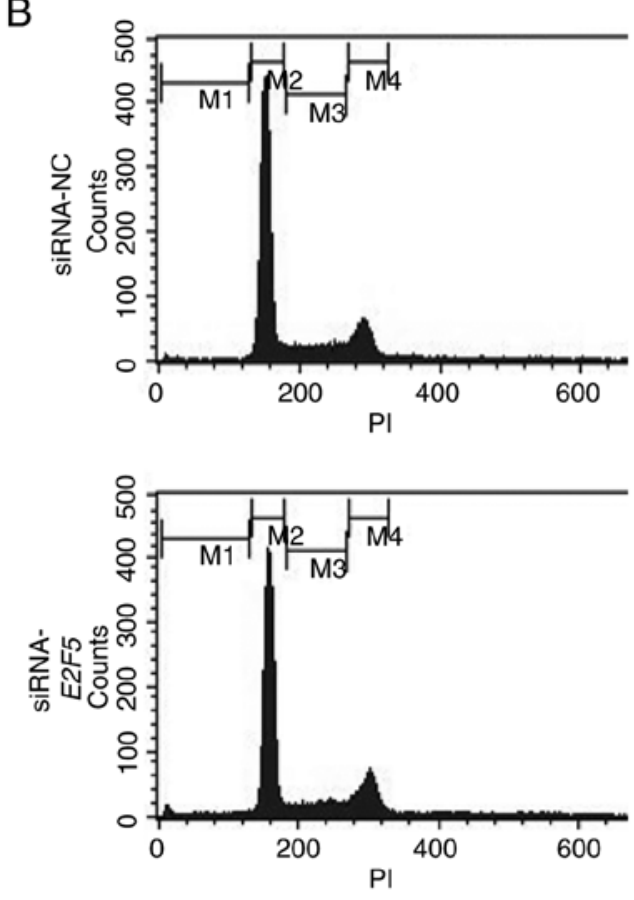

D

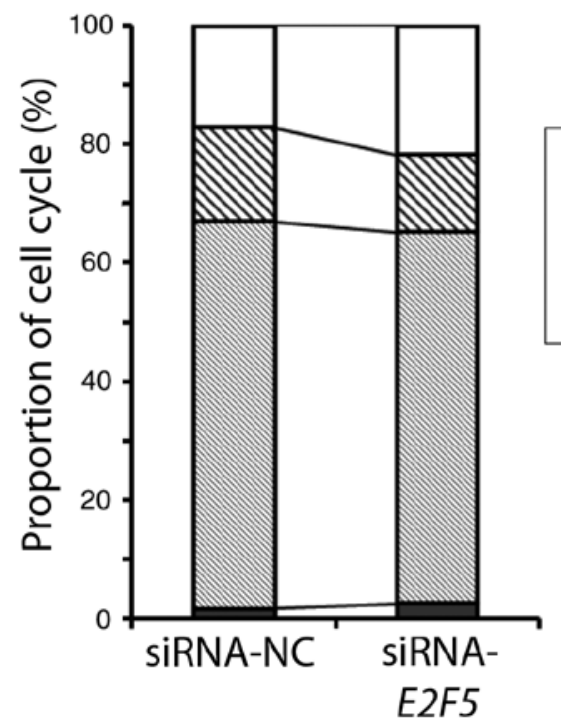

Figure 3. E2F5 depletion enhances cell death of MCF7 cells but not MDA-MB-231 cells. (A and C) MCF7 and (B and D) MDA-MB-231 cells were transfected as described in Fig. 2. Four days after transfection, floating and adherent cells were harvested and stained with propidium iodide. Their cell cycle distributions were then analyzed by FACS. The experiments were performed at least three times. Representative histograms for (A) MCF7 and (B) MDA-MB-231 cells are presented. E2F5, E2F transcription factor 5; FACS, fluorescent-activated cell sorting.

TA-3' (sense) and 5'-AGGAGTCCCATGATGAGATTGT-3' (antisense). The reaction for $p 21^{W A F I}$ and $B A X$ was carried out at $95^{\circ} \mathrm{C}$ for $5 \mathrm{sec}, 55^{\circ} \mathrm{C}$ for $10 \mathrm{sec}$ and $72^{\circ} \mathrm{C}$ for $10 \mathrm{sec}$, for total of 40 cycles. The reaction for NOXA and PUMA was carried out at $95^{\circ} \mathrm{C}$ for $5 \mathrm{sec}$ and $60^{\circ} \mathrm{C}$ for $20 \mathrm{sec}$, for total of 40 cycles. Assessments were performed three times. A mixture of cDNA generated from total RNA of MCF7 and MDA-MB-231 cells was used as a reference. A cDNA mixture dilution series was prepared and used for real-time RT-qPCR as templates to obtain a standard curve for each gene. The housekeeping gene $\beta$-actin was used as an internal reference.

Immunoblotting. Cells were lysed in RIPA buffer containing protease inhibitor cocktail (Nacalai Tesque, Inc.) and phos- phatase inhibitor cocktail (Nacalai Tesque, Inc.), followed by a brief sonication (BIORUPTOR UDC250; Cosmo Bio). Protein concentration of the lysates was measured using Bio-Rad DC kits (Bio-Rad Laboratories, Inc.). The lysates containing $15 \mu \mathrm{g}$ protein/lane were separated by 4-12\% SDS-polyacrylamide gel electrophoresis (SDS-PAGE) and then electroblotted onto Immobilon-P membranes (EMD Millipore). Membranes were blocked with Blocking-one (Nacalai Tesque, Inc.) overnight at $4^{\circ} \mathrm{C}$, and incubated with anti-E2F5 (dilution 1:500; cat. no. GTX129491; GeneTex, Inc.), anti-TP53 (DO1; dilution 1:1,000; cat. no. sc-126; Santa Cruz Biotechnology, Inc.), anti-phospho-TP53 at Ser-15 (dilution 1:1,000; product no. 9284; Cell Signaling Technology, Inc.), anti-p21 ${ }^{\mathrm{WAF} 1}$ (dilution 1:500; cat. no. sc-756; Santa Cruz Biotechnology, Inc.), anti-BAX 

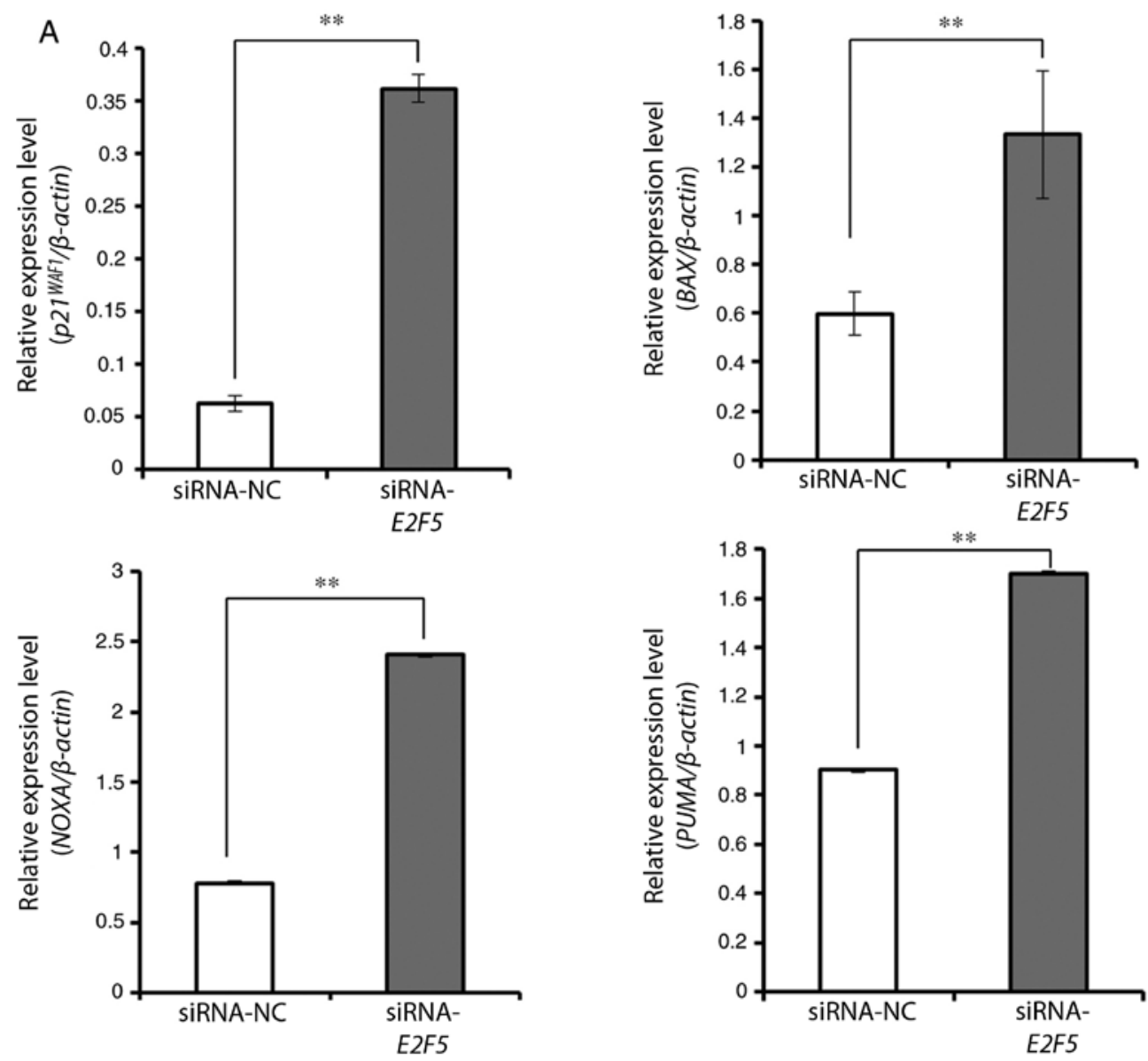

B
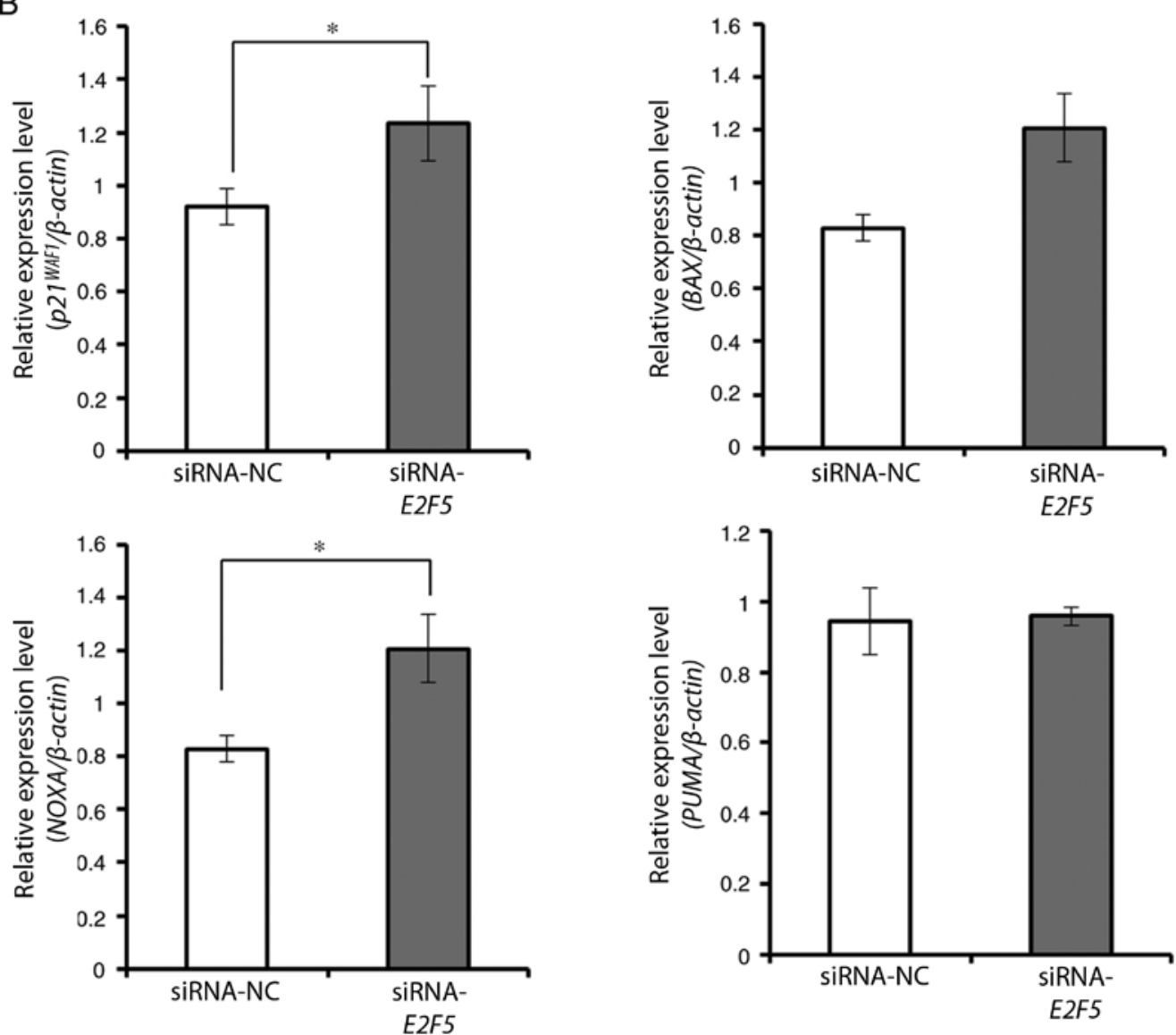

Figure 4. Silencing of E2F5 in MCF7 cells induces several TP53-target genes. (A) MCF7 and (B) MDA-MB-231 cells were transfected as described in Fig. 2. Four days after transfection, total RNA was prepared and analyzed for $p 21^{W A F I}, B A X, N O X A$ and PUMA expression by real-time RT-qPCR. $\beta$-actin was used as an internal control. Data are presented as the means $\pm \mathrm{SD}$ of measurements performed in triplicate. ${ }^{*} \mathrm{P}<0.05,{ }^{* * *} \mathrm{P}<0.01$. E2F5, E2F transcription factor 5 ; RT-qPCR, reverse transcription-quantitative PCR. 
A
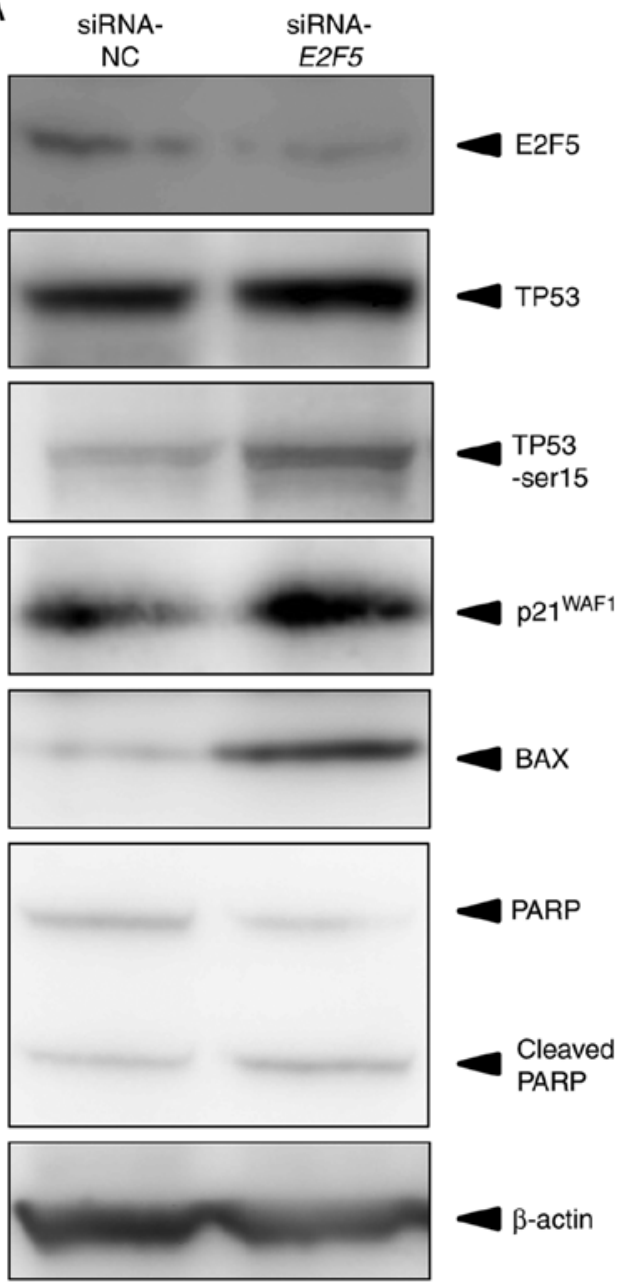

C

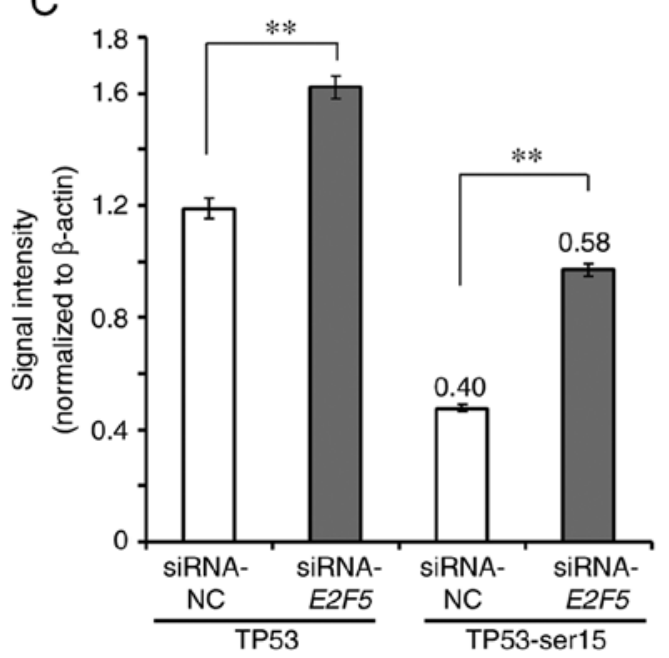

B
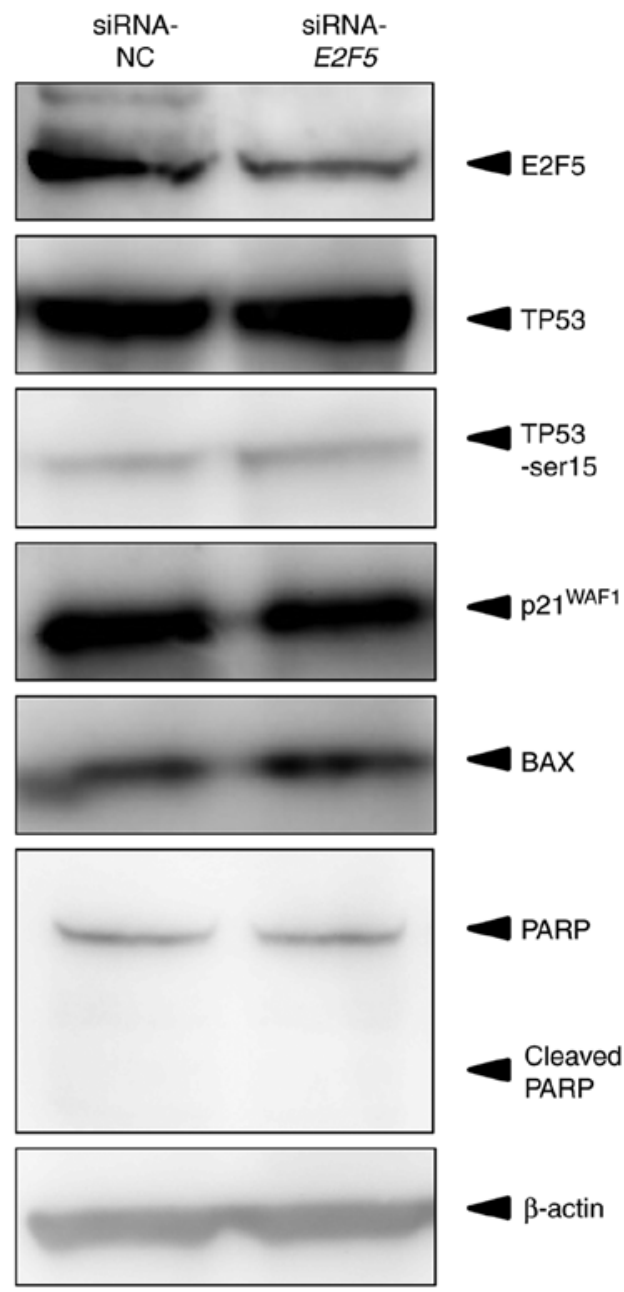

D

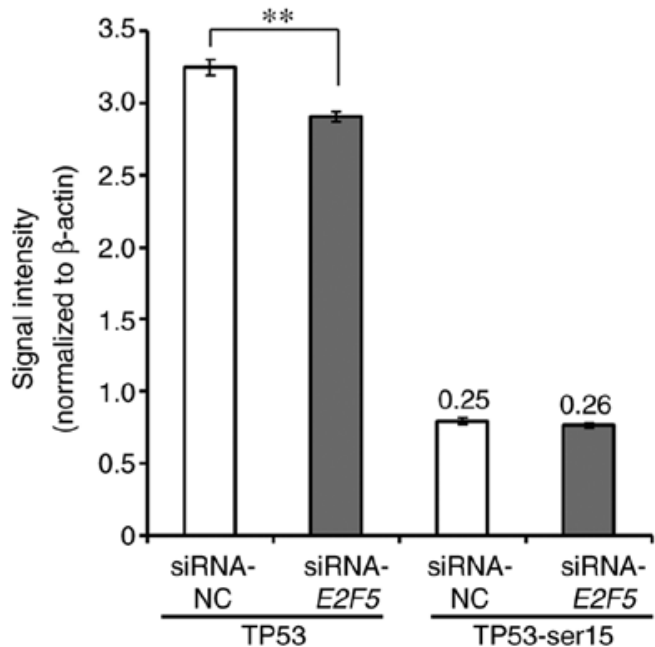

Figure 5. Knockdown of E2F5 in MCF7 but not in MDA-MB-231 cells stimulates several TP53-target gene products. (A) MCF7 and (B) MDA-MB-231 were transfected as in Fig. 3. Four days after transfection, cell lysates were prepared and analyzed for TP53 and its target proteins by immuneblotting. $\beta$-Actin was used as a loading control. (C and D) The signal intensity of TP53 and phosphorylated TP53 in (C) MCF7 and (D) MDA-MB-231 are presented. Data were normalized to the signal intensity of $\beta$-actin. The values over the bar graphs indicate the intensity ratio of phosphorylated TP53 to TP53. Data are presented as the means \pm SD of measurements performed in triplicate. ${ }^{* *} \mathrm{P}<0.01$. E2F5, E2F transcription factor 5.

(dilution 1:1,000; cat. no. 2772; Cell Signaling Technology, Inc.), anti-PARP (dilution 1:1,000; product no. 9542; Cell Signaling Technology, Inc.) or with anti- $\beta$-actin antibody (dilution 1:5,000; product no. A5441; Sigma-Aldrich; Merck KGaA) at $4^{\circ} \mathrm{C}$. After $24 \mathrm{~h}$ of incubation, the membranes were washed with Tris-buffered saline containing $0.1 \%$ Tween-20 (TBS-T), followed by incubation with horseradish peroxidase-conjugated secondary antibodies for mouse (dilution 1:2,000; cat. 

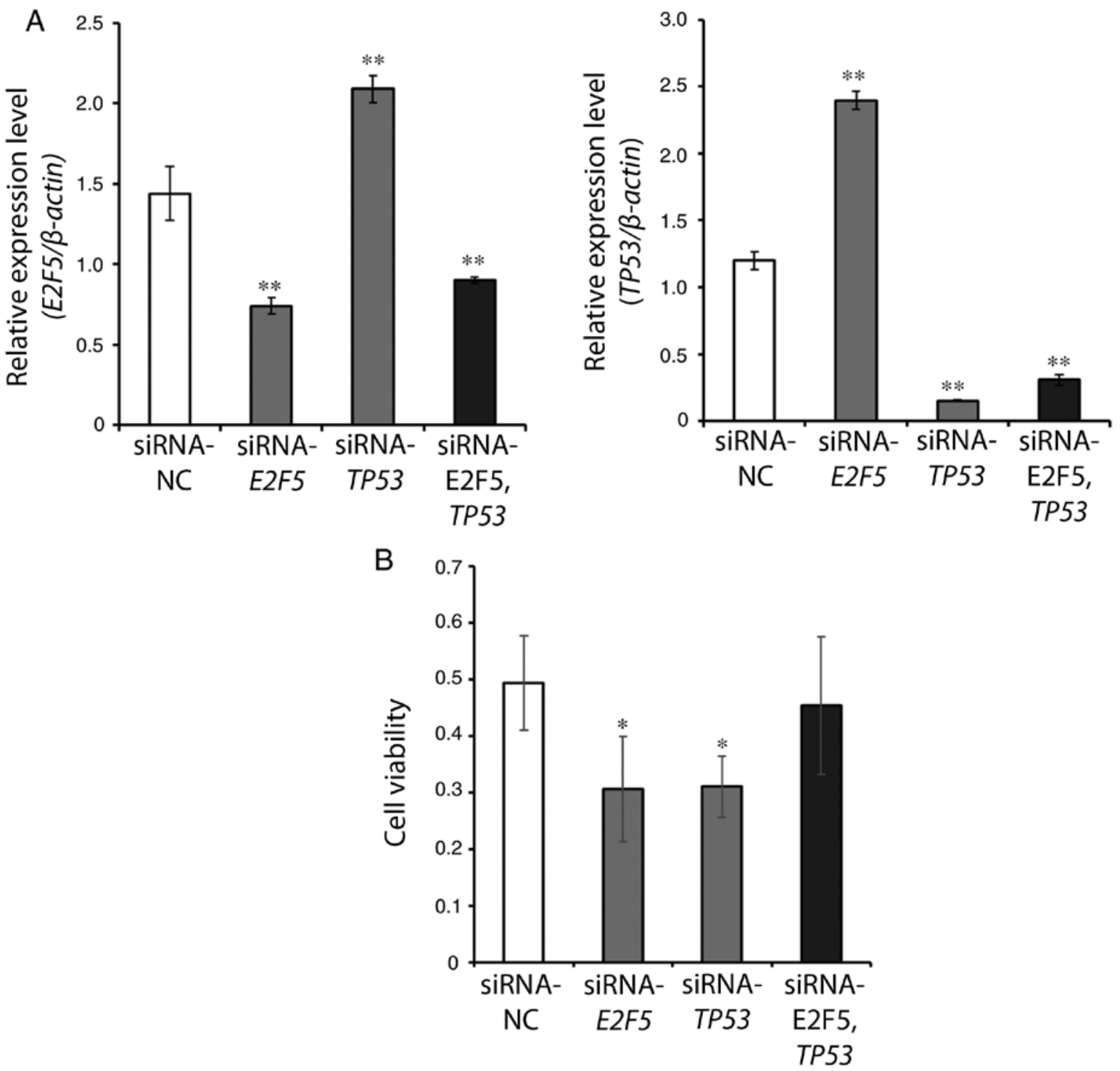

Figure 6. Knockdown of TP53 expression in E2F5-silenced MCF7 reveals a similar phenotype to control cells. (A) MCF7 cells were transfected with E2F5 siRNA, TP53 siRNA, both E2F5 siRNA and TP53 siRNA, or with control siRNA. Total RNA was extracted $48 \mathrm{~h}$ after transfection, and analyzed for $E 2 F 5$ and $T P 53$ expression by real-time RT-qPCR. $\beta$-Actin was used as an internal control. Data are presented as the means \pm SD of measurements performed in triplicate. Significant differences with siRNA-NC were indicated as ${ }^{* *} \mathrm{P}<0.01$. (B) MCF7 cells were transfected as described in A, and viabilities of the cells were measured by the standard WST8 assay 4 days after transfection. Data are presented as the means \pm SD of measurements performed in triplicate. Significant differences with siRNA-NC were indicated as ${ }^{*} \mathrm{P}<0.05$.

no. NA931V) or for rabbit (dilution 1:2,000; cat. no. NA934V; both GE Healthcare Life Sciences) for $1 \mathrm{~h}$ at room temperature. The membranes were washed extensively with TBS-T, and treated with Chemi-Lumi-One Super (Nacalai Tesque, Inc.) to visualize immunoreactivity using LAS4000 (Fujifilm). Intensity of the bands for TP53 and phosphorylated TP53 were measured by ImageJ software ver. 1.48 (National Institutes of Health).

Statistical analysis. Statistical analyses to examine the significance of differences between paired data were performed by Student's t-test, and one-way ANOVA followed by post hoc Tukey test was used to examine significance of differences among multiple data. All of the statistical analyses were performed using JMP software ver. 11.2 (SAS Institute, Inc.). Data are presented as the means \pm SD from at least three independent experiments. In all analyses, $\mathrm{P}<0.05$ was considered to indicate a statistically significant difference.

\section{Results}

Knockdown of E2F5 suppresses the proliferation of breast cancer cells. To clarify the potential role of E2F5 in the development and/or the progression of breast cancer, the expression level of $E 2 F 5$ in the triple-negative-type breast cancer MDA-MB-231 cells, HER2-positive-type breast cancer BT474 cells, plus the luminal-type breast cancer MCF7 and MDA-MB-175VII cells, was examined. As revealed in Fig. 1, real-time RT-qPCR analysis demonstrated that there were no significant differences in the E2F5 expression levels among the cell lines examined. MDA-MB-231 (triple-negative-type) and MCF7 (luminal-type) cells were used for further experiments.

siRNA-mediated knockdown of E2F5 in MCF7 and MDA-MB-231 cells was then performed. Under the experimental conditions, E2F5 mRNA and protein expression levels 

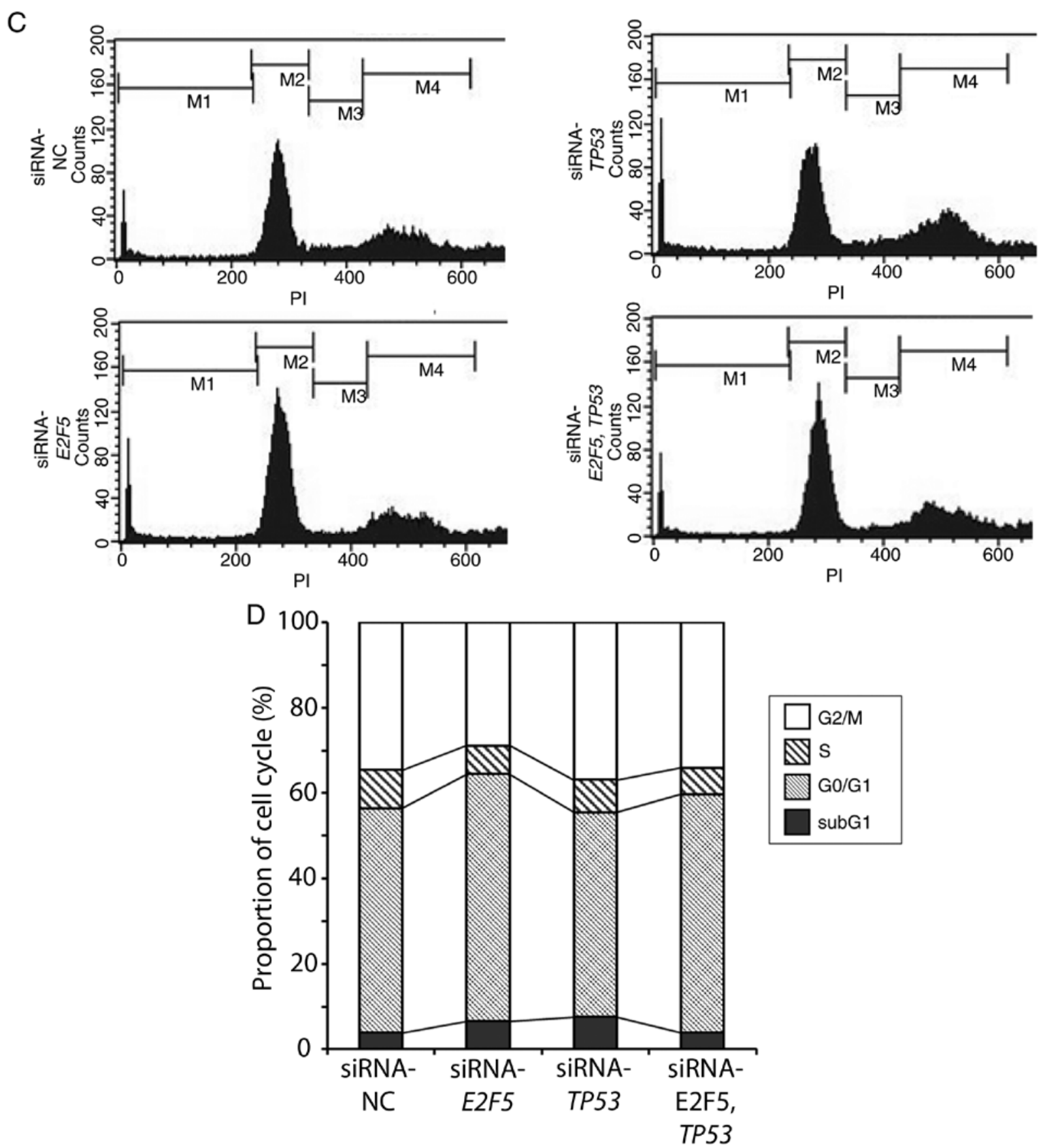

Figure 6. Continued. Knockdown of TP53 expression in E2F5-silenced MCF7 reveals a similar phenotype to control cells. (C and D) MCF7 cells were transfected as in A, and then floating and adherent cells were harvested, 4 days after the transfection. Cells were stained with propidium iodide, and their cell cycle distributions were analyzed by FACS. The experiments were performed at least three times. Representative histograms are presented in C. E2F5, E2F transcription factor 5; RT-qPCR, reverse transcription-quantitative PCR; FACS, fluorescent-activated cell sorting.

were efficiently downregulated in MCF7 (Fig. 2A and C) and MDA-MB-231 cells (Fig. 2B and D). Next, the possible effects of $E 2 F 5$ downregulation on cell proliferation were examined. As revealed in Fig. 2E and F, downregulation of E2F5 expression caused a significant decrease in the proliferation rates of MCF7 and MDA-MB-231 cells, indicating that E2F5 may regulate proliferation of breast cancer cells regardless of their subtype.

E2F5 downregulation potentiates cell death in MCF7 cells but not MDA-MB-231 cells. Since E2F5 knockdown resulted in a significant decrease in the proliferation rates of MCF7 and MDA-MB-231 cells, the possible effects of E2F5 knockdown on cell cycle distribution was examined.FACS analysis demonstrated a clear increase in the proportion of cells with sub-G1 DNA content, indicating that the proportion of dead cells was increased, in E2F5-knockdown MCF7 cells in comparison to control cells (Fig. 3A and C). In contrast, depletion of E2F5 had no detectable effect on the number of MDA-MB-231 cells with sub-G1 DNA content (Fig. 3B and D). Further analysis of these results indicated that the proportion of mitotic cells was marginally increased in E2F5-knockdown MDA-MB-231 cells relative to the control cells (Fig. 3D). These observations indicated that $E 2 F 5$ may regulate breast cancer cell proliferation through distinct mechanisms in different types of cells. 

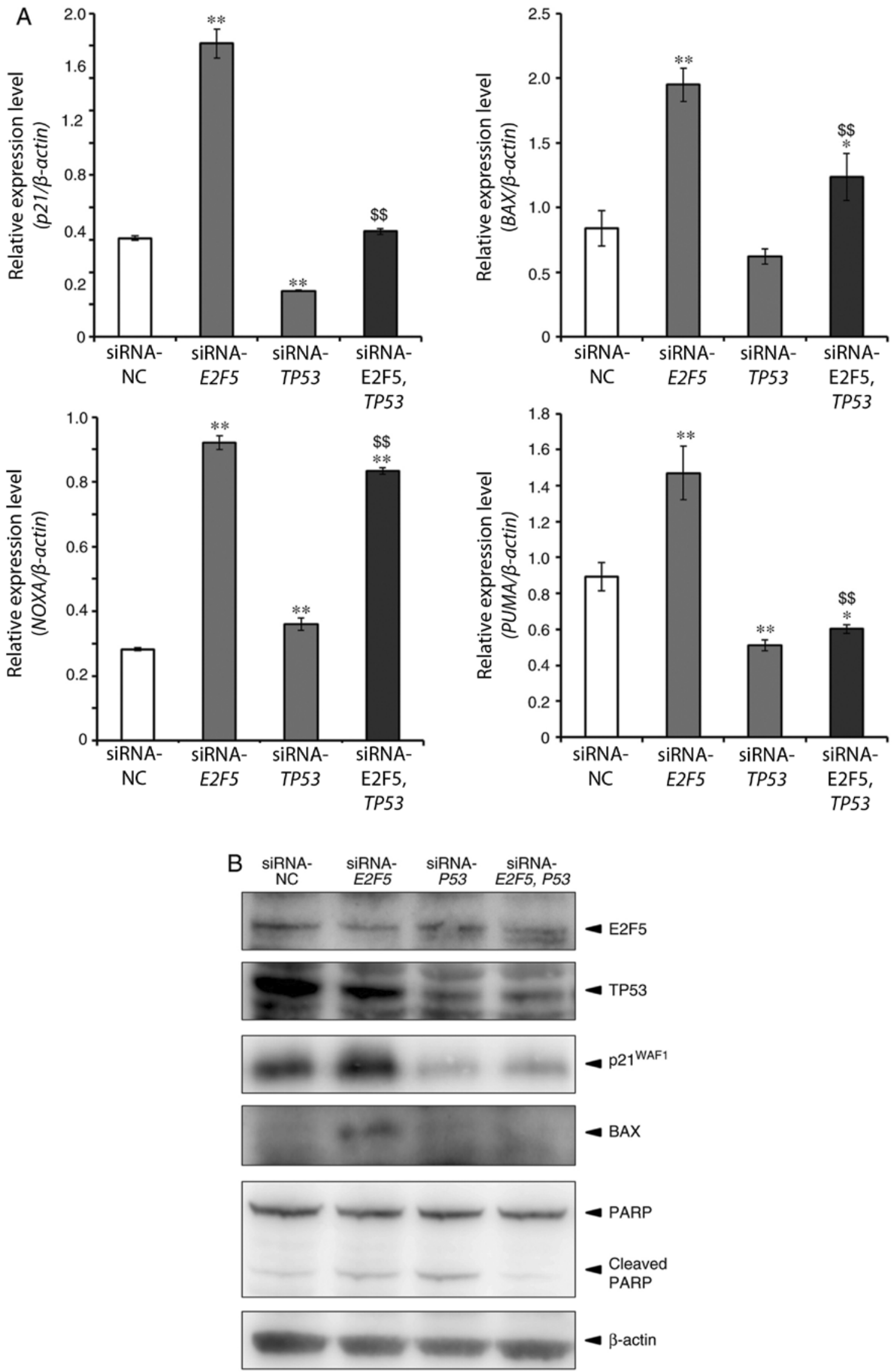

Figure 7. Knockdown of TP53 expression in MCF7 suppresses the induction of several TP53 target genes by E2F5 knockdown. (A) MCF7 cells were transfected as described in Fig. 6. Four days after transfection, total RNA was prepared and analyzed for $p 21^{W A F 1}, B A X, N O X A$ and $P U M A$ expression by real-time RT-qPCR. $\beta$-Actin was used as an internal control. Data are presented as the means \pm SD of measurements performed in triplicate. Significant difference with siRNA-NC was indicated as ${ }^{*} \mathrm{P}<0.05,{ }^{* *} \mathrm{P}<0.01$. Significant difference between siRNA-E2F5 and siRNA-E2F5, TP53 was indicated as $\$ \$ \mathrm{P}<0.01$. (B) MCF7 cells were transfected as described in Fig. 6. Four days after transfection, cell lysates were prepared and analyzed for TP53 and its target proteins by immunoblotting. $\beta$-Actin was used as a loading control. E2F5, E2F transcription factor 5; RT-qPCR, reverse transcription-quantitative PCR. 
E2F5 gene silencing triggers TP53-mediated cell death in MCF7 cells but not in MDA-MB-231 cells. Finally, the molecular mechanisms underlying the cell death mediated by $E 2 F 5$ knockdown in MCF7 cells were examined. As MCF7 cells carry the wild-type TP53 (23) and MDA-MB-231 cells carry mutant TP53 (23), we postulated that knockdown of E2F5 in MCF7 induced cell death via the TP53-dependent pathway. The observation that the effects of E2F5 knockdown in BT474 cells carrying mutant TP53 (23) were similar to those in MDA-MB-231 cells (Fig. S1A) supported this theory. Real-time RT-qPCR experiments revealed that several TP53-target genes implicated in the induction of cell cycle arrest and/or cell death including $p 21^{W A F I}, B A X, N O X A$ and $P U M A$ were significantly upregulated in $E 2 F 5$-depleted MCF7 cells compared to control cells (Fig. 4A). In contrast, E2F5 gene silencing resulted in induction of $p 21^{W A F 1}$ and NOXA but not of BAX and PUMA in TP53-mutant MDA-MB-231 cells (Fig. 4B). In another TP53-mutant cell line BTB474, silencing of E2F5 induced all of the TP53 target genes aforementioned except PUMA, but to a lesser degree (Fig. S2A). To further confirm these results, immunoblotting analysis was performed. Consistent with the results of real-time RT-qPCR, E2F5 depletion promoted the expression of $\mathrm{p} 21^{\mathrm{WAF} 1}$ and BAX in MCF7 cells (Fig. 5A). The level of cleaved PARP was clearly increased, and the expression levels of TP53 and phosphorylated TP53 at Ser-15 were increased in E2F5-knockdown cells (Fig. 5A and C). The intensity ratio of phosphorylated TP53 to TP53 was also higher in E2F5-knockdown cells compared to control cells (Fig. 5C). In a sharp contrast to MCF7 cells, knockdown of E2F5 expression in MDA-MB-231 cells had a negligible effect on the expression levels of $\mathrm{p} 21^{\mathrm{WAF} 1}$ and BAX, and the expression levels of TP53 and phosphorylated TP53 at Ser-15 were not altered by E2F5 knockdown (Fig. 5B and D). Similar results as in MDA-MB-231 cells were also obtained in BT474 cells (Fig. S2B and C).

Silencing of TP53 cancels the effect of E2F5 silencing in $M C F 7$ cells. Since the results outlined above indicated that E2F5 regulates cellular proliferation and cell death in a TP53-dependent manner in MCF7 cells, the effects of E2F5 silencing in TP53-silenced MCF7 cells were next examined (Fig. 6A). As revealed in Fig. 6B, the viability of MCF7 cells transfected with both E2F5 siRNA and TP53 siRNA was almost the same as that of control cells. In addition, the proportion of double-knockdown cells with sub-G1 DNA was also the same as the control cells (Fig. 6C and D). Real-time RT-qPCR analysis demonstrated that induction of $p 21^{W A F I}, B A X$ and PUMA by E2F5 depletion was significantly suppressed by co-depletion of TP53 in comparison to siRNA-E2F5 (Fig. 7A). The level of NOXA expression was also significantly reduced in the double-knockdown cells compared to the cells in which only E2F5 was silenced, however the extent of the reduction was not as marked as in the other 3 genes (Fig. 7A). Consistent with these results, induction of $\mathrm{p} 21^{\mathrm{WAF} 1}$ and $\mathrm{BAX}$ and increase in the level of cleaved PARP in E2F5-silenced cells were strongly suppressed by co-transfection with TP53 siRNA (Fig. 7B).

\section{Discussion}

The results in the present study demonstrated that knockdown of $E 2 F 5$ expression decreased the proliferation rate of breast cancer cells, including luminal-type breast cancer-derived MCF7 cells, TNBC-derived MDA-MB-231 cells, and HER2-positive-type BT474 cells. Cell cycle analysis revealed that cell death was induced in E2F5-knockdown MCF7 cells, whereas E2F5 depletion had only a marginal effect on MDA-MB-231 and BT474 cells carrying mutant TP53. Notably, E2F5 gene silencing in MCF7 cells stimulated the transcription of TP53-target genes, such as $p 21^{W A F 1}, B A X$, NOXA and PUMA. In contrast to MCF7 cells, knockdown of E2F5 in MDA-MB-231 cells induced the transcription of $p 21^{W A F I}$ and NOXA but not of BAX and PUMA. In BT474 cells, E2F5 knockdown induced all of these TP53 target genes except PUMA, but to a lower extent compared to MCF7 cells. As MCF7 cells carry the wild-type TP53, and MDA-MB-231 and BT474 cells carry the mutated TP53, these results indicated that E2F5 regulates cell death through a TP53-dependent pathway in MCF7 cells. The observation that silencing of TP53 ameliorated the effects of E2F5 silencing in MCF7 supports this theory.

E2F4 and E2F5 are highly expressed in quiescent cells (21), and their expression has been revealed to be required for pocket protein-mediated G1 arrest in fibroblasts (22). Based on these observations, E2F5 is expected to be a tumor-suppressor, however, there is accumulating evidence that E2F5 may have a potential pro-oncogenic function in numerous types of human cancer (13-17). In fact, the aberrant overexpression of E2F5 has been observed in a variety of malignancies including breast cancer $(20,24,25)$. The molecular basis of the aforementioned dual roles of E2F5 has yet to be elucidated. It has been reported that E2F4 contributes to the formation of cyclin E repressor complex (CREC), which plays a pivotal role in the transcription of cyclin E1 during G1 phase, and thereby blocks cellular proliferation (26). These findings suggest that the aberrant expression of E2F4 may cause uncontrolled cell division. Consistent with these observations, unlike E2F4, E2F5 is not implicated in the complex formation of CREC.

The results presented herein revealed that $\mathrm{E} 2 \mathrm{~F} 5$ regulated the cellular proliferation and cell death of MCF7 cells in a wild-type TP53-dependent manner. In support of this theory, knockdown of E2F5 expression resulted in upregulation of TP53 target downstream genes involved in the induction of cell cycle arrest and/or cell death in MCF7 cells carrying wild-type TP53. The observations of cells with depletion of both E2F5 and TP53 suggested that at least $p 21^{\text {WAFl }}, B A X$ and $P U M A$ were induced by $E 2 F 5$ depletion in a TP53-dependent manner. Although it has been reported that TP53 may regulate the activity of E2F4 and E2F5 (27), complex formation between TP53 and E2F4/E2F5 was not detected (27). Similar to these previous results, the TP53/E2F5 complex was also undetectable under our experimental conditions (data not shown).

In contrast to MCF7 cells, E2F5 depletion in TP53-mutant MDA-MB-231 and BT474 cells attenuated cellular proliferation but did not trigger cell death. The expression level of mutant TP53 is usually markedly higher than that of wild-type TP53 (28), and mutant TP53 is known to disturb the pro-apoptotic function of wild-type TP53 (29). The results of the present study also confirmed that the expression levels of TP53 in breast cancer carrying mutant TP53 were markedly higher than in breast cancer cells with wild-type TP53. Therefore, it 
is possible that the induction of cell death by wild-type TP53 may be suppressed by mutant TP53 in the MDA-MB-231 and BT474 cells. The present results revealed that the proportion of cells with G2/M DNA content was slightly increased in E2F5-depleted MDA-MB-231 cells. Recently, it has been reported that knockdown of $E 2 F 5$ expression in prostate cancer cells resulted in activation of p38 MAPK and SMAD3 pathways, and increased the number of cells with G1 DNA content but not of cells with G2/M DNA content (30). In non-small-cell lung cancer cells, E2F5 may act as a transcriptional repressor of p21 ${ }^{\mathrm{WAF} 1}$ (19). However, a significant change in the expression level of $\mathrm{p} 21^{\mathrm{WAF} 1}$ by $E 2 F 5$ depletion in MDA-MB-231 cells was not detected. In addition, no increase in proportion of the cells in $\mathrm{G} 2 / \mathrm{M}$ phase was observed in BT474 cells. Further analyses are required to clarify the molecular mechanisms underlying E2F5-mediated regulation of the cell cycle in TP53-mutant breast cancer cells.

In conclusion, the present study revealed that E2F5 participated in the carcinogenesis of breast cancer carrying wild-type TP53 through the suppression of TP53, while E2F5 had a pro-proliferative but not anti-apoptotic function in TP53-mutated breast cancer. At present, the precise molecular mechanisms of how TP53 could suppress the cellular proliferation of TP53-mutated breast cancer cells has yet to be elucidated. To adequately understand these mechanisms, further study using an increased number of breast cancer cells should be conducted. It is also well-known that estrogen signaling has a crucial role in the development of breast cancer, however, we did not extend our present study to address the functional relationship of E2F5 and estrogen signaling. Further analysis using numerous types of breast cancer cell lines with or without estrogen receptor are required. Moreover, in vivo xenograft experiments may provide insights into the vital roles of E2F5 in breast cancer development.

\section{Acknowledgements}

We thank Ms. K. Tagata (Division of General Medicine, Department of Medicine, Nihon University School of Medicine) for her secretarial assistance.

\section{Funding}

The present study was supported in part by MEXT-Supported Program for the Strategic Research Foundation at Private Universities (2011-2015) to KF, MS, and NF.

\section{Availability of data and materials}

The datasets used during the present study are available from the corresponding author upon reasonable request.

\section{Authors' contributions}

$\mathrm{KF}, \mathrm{NF}, \mathrm{MS}, \mathrm{TO}$ and SM planned the experiments. YIn, DW, $\mathrm{KF}$, YIs, AO, ToT, TaT and TO performed the experiments. NF performed statistical analysis. KF, TO and SM wrote the manuscript. KF, NF, MS, TO and SM critically revised the manuscript and all the authors provided final approval of the manuscript to be published.

\section{Ethics approval and consent to participate}

Not applicable.

\section{Patient consent for publication}

Not applicable.

\section{Competing interests}

The authors declare that they have no competing interests.

\section{References}

1. Ginsburg O, Bray F, Coleman MP, Vanderpuye V, Eniu A, Kotha SR, Sarker M, Huong TT, Allemani C, Dvaladze A, et al: The global burden of women's cancers: A grand challenge in global health. Lancet 389: 847-860, 2017.

2. Lalloo F and Evans DG: Familial breast cancer. Clin Genet 82: 105-114, 2012.

3. Perou CM, Sørlie T, Eisen MB, van de Rijn M, Jeffrey SS, Rees CA, Pollack JR, Ross DT, Johnsen H, Akslen LA, et al: Molecular portraits of human breast tumours. Nature 406: 747-752, 2000.

4. Sørlie T, Perou CM, Tibshirani R, Aas T, Geisler S, Johnsen H, Hastie T, Eisen MB, van de Rijn M, Jeffrey SS, et al: Gene expression patterns of breast carcinomas distinguish tumor subclasses with clinical implications. Proc Natl Acad Sci USA 98: 10869-10874, 2001.

5. Sorlie T, Tibshirani R, Parker J, Hastie T, Marron JS, Nobel A, Deng S, Johnsen H, Pesich R, Geisler S, et al: Repeated observation of breast tumor subtypes in independent gene expression data sets. Proc Natl Acad Sci USA 100: 8418-8423, 2003.

6. Coussens L, Yang-Feng TL, Liao YC, Chen E, Gray A, McGrath J, Seeburg PH, Libermann TA, Schlessinger J, Francke U, et al: Tyrosine kinase receptor with extensive homology to EGF receptor shares chromosomal location with neu oncogene. Science 230: 1132-1139, 1985.

7. Akiyama T, Sudo C, Ogawara H, Toyoshima $\mathrm{K}$ and Yamamoto T: The product of the human c-erbB-2 gene: A 185-kilodalton glycoprotein with tyrosine kinase activity. Science 232: 1644-1646, 1986.

8. Perou CM: Molecular stratification of triple-negative breast cancers. Oncologist 16 (Suppl 1): S61-S70, 2011.

9. Xanthoulis A and Tiniakos DG: E2F transcription factors and digestive system malignancies: How much do we know? World J Gastroenterol 19: 3189-3198, 2013.

10. Lees JA, Saito M, Vidal M, Valentine M, Look T, Harlow E, Dyson $\mathrm{N}$ and Helin $\mathrm{K}$ : The retinoblastoma protein binds to a family of E2F transcription factors. Mol Cell Biol 13: 7813-7825, 1993.

11. Dyson N: The regulation of E2F by pRB-family proteins. Genes Dev 12: 2245-2262, 1998.

12. Stevaux O and Dyson NJ: A revised picture of the E2F transcriptional network and RB function. Curr Opin Cell Biol 14: 684-691, 2002

13. Zhao J, Wu XY, Ling XH, Lin ZY, Fu X, Deng YH, He HC and Zhong W: Analysis of genetic aberrations on chromosomal region 8q21-24 identifies E2F5 as an oncogene with copy number gain in prostate cancer. Med Oncol 30: 465, 2013.

14. Ishimoto T, Shiozaki A, Ichikawa D, Fujiwara H, Konishi H, Komatsu S, Kubota T, Okamoto K, Nakashima S, Shimizu H, et al: E2F5 as an independent prognostic factor in esophageal squamous cell carcinoma. Anticancer Res 33: 5415-5420, 2013.

15. Kothandaraman N, Bajic VB, Brendan PN, Huak CY, Keow PB, Razvi K, Salto-Tellez M and Choolani M: E2F5 status significantly improves malignancy diagnosis of epithelial ovarian cancer. BMC Cancer 10: 64, 2010.

16. Lu G, Sun Y, An S, Xin S, Ren X, Zhang D, Wu P, Liao W, Ding Y and Liang L: MicroRNA-34a targets FMNL2 and E2F5 and suppresses the progression of colorectal cancer. Exp Mol Pathol 99: 173-179, 2015.

17. Jiang Y, Yim SH, Xu HD, Jung SH, Yang SY, Hu HJ, Jung CK and Chung YJ: A potential oncogenic role of the commonly observed E2F5 overexpression in hepatocellular carcinoma. World J Gastroenterol 17: 470-477, 2011. 
18. Zou C, Li Y, Cao Y, Zhang J, Jiang J, Sheng Y, Wang S, Huang A and Tang H: Up-regulated MicroRNA-181a induces carcinogenesis in hepatitis B virus-related hepatocellular carcinoma by targeting E2F5. BMC Cancer 14: 97, 2014.

19. Donzelli S, Fontemaggi G, Fazi F, Di Agostino S, Padula F Biagioni F, Muti P, Strano S and Blandino G: MicroRNA-128-2 targets the transcriptional repressor E2F5 enhancing mutant p53 gain of function. Cell Death Differ 19: 1038-1048, 2012.

20. Umemura S, Shirane M, Takekoshi S, Kusakabe T, Itoh J, Egashira N, Tokuda Y, Mori K and Osamura YR: Overexpression of E2F-5 correlates with a pathological basal phenotype and a worse clinical outcome. Br J Cancer 100: 764-771, 2009.

21. Hijmans EM, Voorhoeve PM, Beijersbergen RL, van't Veer LJ and Bernards R: E2F-5, a new E2F family member that interacts with p130 in vivo. Mol Cell Biol 15: 3082-3089, 1995.

22. Gaubatz S, Lindeman GJ, Ishida S, Jakoi L, Nevins JR, Livingston DM and Rempel RE: E2F4 and E2F5 play an essential role in pocket protein-mediated G1 control. Mol Cell 6: 729-735, 2000.

23. Bouaoun L, Sonkin D, Ardin M, Hollstein M, Byrnes G, Zavadil J and Olivier M: TP53 Variations in Human Cancers: New Lessons from the IARC TP53 Database and Genomics Data. Hum Mutat 37: 865-876, 2016.

24. Polanowska J, Le Cam L, Orsetti B, Vallés H, Fabbrizio E, Fajas L, Taviaux S, Theillet C and Sardet C: Human E2F5 gene is oncogenic in primary rodent cells and is amplified in human breast tumors. Genes Chromosomes Cancer 28: 126-130, 2000.
25. Ali A, Ullah F, Ali IS, Faraz A, Khan M, Shah ST, Ali N and Saeed M: Aberrant promoter methylation at $\mathrm{CpG}$ cytosines induce the upregulation of the E2F5 gene in breast cancer. J Breast Cancer 19: 133-141, 2016.

26. Le Cam L, Polanowska J, Fabbrizio E, Olivier M, Philips A, Ng Eaton E, Classon M, Geng Y and Sardet C: Timing of cyclin E gene expression depends on the regulated association of a bipartite repressor element with a novel E2F complex. EMBO J 18: 1878-1890, 1999.

27. Vaishnav YN and Pant V: Differential regulation of E2F transcription factors by $\mathrm{p} 53$ tumor suppressor protein. DNA Cell Biol 18: 911-922, 1999.

28. Strano S, Dell'Orso S, Mongiovi AM, Monti O, Lapi E, Di Agostino S, Fontemaggi G and Blandino G: Mutant p53 proteins: between loss and gain of function. Head Neck 29: 488-496, 2007.

29. Ozaki T and Nakagawara A: Role of p53 in cell death and human cancers. Cancers (Basel) 3: 994-1013, 2011.

30. Majumder S, Bhowal A, Basu S, Mukherjee P, Chatterji U and Sengupta S: Deregulated E2F5/p38/SMAD3 circuitry reinforces the pro-tumorigenic switch of TGF $\beta$ signaling in prostate cancer. J Cell Physiol 231: 2482-2492, 2016. 